\title{
A Study on the Short-Term Market Effect of China A-share Private Placement and Medium and Small Investors' Decision-Making
}

\author{
Shuangjun Li
}

\author{
Department of Finance, Beijing Jiaotong University No.3 Shangyuancun Haidian District Beijing \\ 100044 P. R. China \\ 253232543@qq.com
}

\begin{abstract}
Keywords: Private Placement, Announcement Effect, Insider Trading
Abstract. Since A-share market achieved full circulation after the non-tradable share reform in 2006, the private placement has been the main equity refinancing method of the listed companies in Chinese stock market. Mainly adopting the method of event study, this paper uses 867 listed companies which implemented the private placement from 2013 to 2015 as the sample to analyze the market effect during the public announcement period. The private placement has been proved empirically to bring the obvious significant abnormal return during the announcement period. Besides, the amount of excess earnings varies when different modes of private placement is adopted. Therefore, different levels of market effects require the small and medium-sized investors to adopt the corresponding investment decision-makings.
\end{abstract}

\section{Introduction}

Private placement is the non-public offering of shares to a few specific investors. Generally, the listed companies which come up with non-public offering Plans and are accepted by the market are more likely to grow and develop well. The private placement will usually improve both the company's profits and management. Therefore, the announcement of private placement incident generally does good to the listed companies. It can attract attention in the secondary market and cause the super-normal fluctuation of share price. As medium and small investors in the secondary market are at a disadvantage in fund and information, this study shall provide advice about decision making for them to better participate in private placement .

\section{Literature References}

The research scholars in United States began earlier to study the private placement, Wruck (1989) found that the private placement average abnormal return reaches $4.5 \%$ after announcement, the greater the ownership concentration after the announcement is, The larger the value of the company. Hertzel and Smith (1993) based on the Nasdaq's 106 private placement companies from1980 to 1987 and proved that there is a positive announcement effect in the US stock market. Olaf Stotz (2010) analyzed the 1999 and 2008 private placement of 689 samples and found a positive announcement effect, he still found that the small-cap stock of private placement have more abnormal return than the large-cap stock. Wu, Wang, and Yao (2005) show positive announcement effects for private placements by non-financial and non-utility firms listed on the Stock Exchange of Hong Kong (SEHK) for the period 1989-1997. They find no evidence for monitoring effect of private equity placements. According to them, sufficiently close incentive alignment at high level of ownership concentration facilitates positive information effects.

\section{Research Design}

3.1 Sample Selection and Data Sources. The sample consists of 867 listed companies in china, which announced private placement plan during the period under study, that is, from 2013 to 2015. After culling, we got 867 useful samples in total, and samples were further subdivided into reorganization pattern (73), asset injection pattern (328) and project financing pattern (466). Most of the data from the Wind database and GTA database, a small part of the additional data from 
RESSET database.

3.2 Research Methods and Research Procedures. This paper mainly adopts the Event Study Method to study the market effect during the listed company private placement announcement period.

This article will elect the board of directors selected plan announcement for the event date. Based on the results of predecessors this paper determines that the event window for the first 10 trading days of the event and after 5 days, that is $(-10,+5)$, a total of 16 trading days as the event window period. This paper argues that the estimation period should be about five times the length of the window period is reasonable, so the paper set the estimation period is 80 days, corresponding to the time interval $(-90,-11)$.

This paper uses the MATLAB to edit the program to calculate the abnormal return in order to reduce the amount of calculation.

\section{Empirical Analysis on the Market Effects of Private Placement.}

This paper will set the cumulative abnormal return rate (CAAR) and the average abnormal return rate (AAR) during the event window as proxy variables, to measure the announcement effect and insider trading effect of the private placement incident. according to the structure and modes of the samples, there are three types of private placement: asset reorganization, asset injection and project financing. In this way, we can further research into the market effects of different types of private placement.

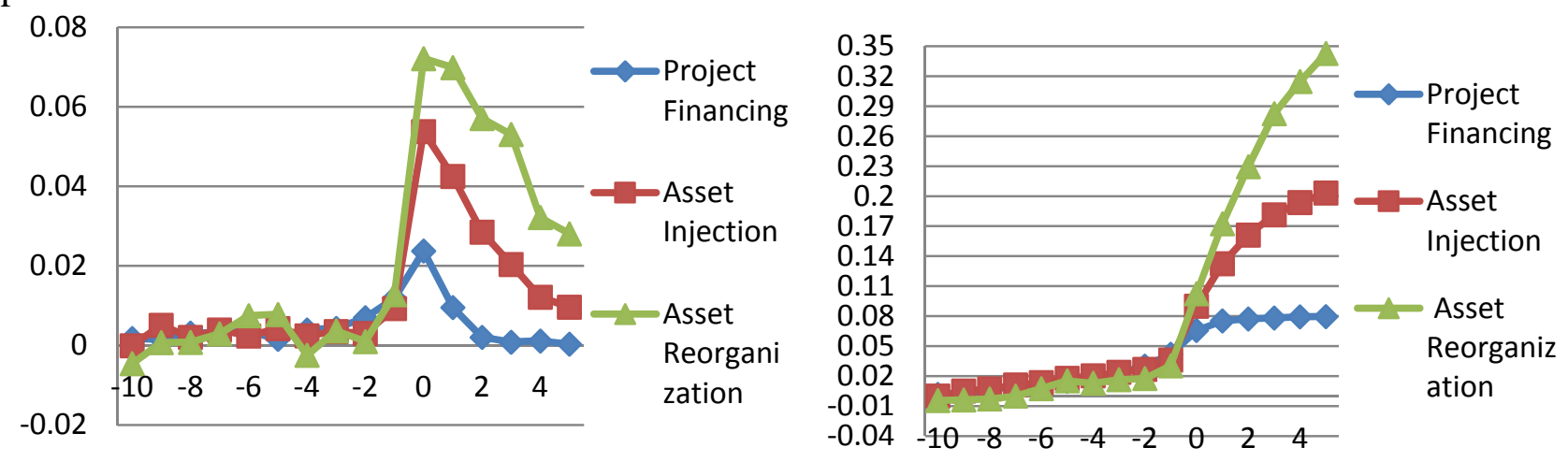

Fig. 1 The Trend of the AARs

Fig.2 The Trend of the CAARs

4.1 The Average Abnormal Return Rate (AAR). Fig.1 presents that different types of private placement incidents have different degrees of market effects. The asset reorganization mode has a strongest announcement effect, as a result of which, the AAR reaches about $7 \%$ on the announcement day (if suspended, taking the next trading day). While asset injection mode comes the second of which the AAR is around 5\%, project financing mode generate the least reaction in market as its AAR is only a bit higher than $2 \%$. But the overall trend suggests that the market reacted before the announcement of the private placement incident, thus the ARR increased gradually during the window period $(-5,0)$, typically in the asset injection and project financing modes. Oppositely, when it comes to significant asset reorganization, the stock price was suppressed obviously before the announcement day. Provided the purposes and modes of different private placement incidents, this result shows that key information may be released partially before the announcement, which means there is a problem of insider information leakage in China's A-share market.

4.2 The Cumulative Average Abnormal Return Rates (CAARs).The cumulative abnormal return rate reflects the excess earnings accumulated during the event window period. As shown in Fig.2, different types of private placement vary in levels of accumulated excess earnings. The CAAR of the asset reorganization mode during the window period $(-10,5)$ is up to about $30 \%$, while 
that of the asset injection mode reaches $20 \%$. As for the project financing mode, its CARR is about $8 \%$. Judging by the trend, most of the cumulative abnormal returns are generated after the window period $(0,+5)$ and tend to stabilize from 5 days after the announcement day. The cumulative returns of private placement in the project financing mode is stabilized three days after the announcement, the asset injection mode five days. The effect of excess returns in the asset organization mode lasts longer, catching more market's attention. Overall, the private placement is still a positive measure for the market and leads to positive announcement effects.

4.3 The Significance Test of the Abnormal Returns of Private Placement. Tab.1 presents the results of the single variable $T$ tests of AAR and CAAR. The significant differences between the AAR\&CAAR and 0 reveal the different characteristics of the distribution of abnormal returns in different modes.

Tab.1 The Significance Test of the Daily Abnormal Return Rates During the Window Period of Private Placement

\begin{tabular}{crrrrrr}
\hline \hline AAR\&CAAR & \multicolumn{2}{c}{ The Asset Reorganization Mode } & \multicolumn{1}{c}{ The Asset Injection Mode } & The Project Financing Mode \\
\hline Date & \multicolumn{1}{c}{$\mathrm{T}$} & $\mathrm{P}$ & $\mathrm{T}$ & $\mathrm{P}$ & $\mathrm{T}$ & $\mathrm{P}$ \\
-10 & -0.9707 & 0.3350 & 0.6671 & 0.5052 & 1.7196 & $0.0862^{*}$ \\
-9 & 0.7706 & 0.4434 & 2.7418 & $0.0064^{* * *}$ & 1.3036 & 0.1930 \\
-8 & 0.1672 & 0.8677 & 0.9504 & 0.3426 & 2.7499 & $0.0062^{* * *}$ \\
-7 & 0.8729 & 0.3856 & 2.6773 & $0.0078^{* * *}$ & 2.8520 & $0.0045^{* * *}$ \\
-6 & 1.9466 & $0.0555^{*}$ & 0.6694 & 0.5037 & 3.3981 & $0.0007^{* * *}$ \\
-5 & 2.3967 & $0.0191^{* *}$ & 3.0322 & $0.0026^{* * *}$ & 1.6896 & $0.0918^{*}$ \\
-4 & 0.1840 & 0.8546 & 1.2206 & 0.2231 & 3.3224 & $0.0010^{* * *}$ \\
-3 & 0.3645 & 0.7165 & 1.9983 & $0.0465 * *$ & 3.3904 & $0.0008^{* * *}$ \\
-2 & 0.7368 & 0.4636 & 1.2332 & 0.2184 & 5.6508 & $0.0000^{* * *}$ \\
-1 & 3.6263 & $0.0005 * * *$ & 5.0808 & $0.0000^{* * *}$ & 7.8803 & $0.0000^{* * *}$ \\
0 & 13.8346 & $0.0000^{* * *}$ & 19.4640 & $0.0000^{* * *}$ & 10.9931 & $0.0000^{* * *}$ \\
1 & 13.9165 & $0.0000^{* * *}$ & 14.3297 & $0.0000^{* * *}$ & 5.5523 & $0.0000^{* * *}$ \\
2 & 8.5803 & $0.0000^{* * *}$ & 11.6476 & $0.0000^{* * *}$ & 1.6386 & 0.1020 \\
3 & 8.4965 & $0.0000^{* * *}$ & 8.2937 & $0.0000^{* * *}$ & 1.0496 & 0.2944 \\
4 & 5.8430 & $0.0000^{* * *}$ & 6.5226 & $0.0000^{* * *}$ & 1.0960 & 0.2737 \\
5 & 5.4717 & $0.0000^{* * *}$ & 5.2758 & $0.0000^{* * *}$ & -0.0246 & 0.9804 \\
$(-10,-5)$ & 1.9369 & $0.0567 *$ & 4.2835 & $0.0000^{* * *}$ & 5.6811 & $0.0000^{* * *}$ \\
$(-10,0)$ & 8.4481 & $0.0000^{* * *}$ & 16.0224 & $0.0000^{* * *}$ & 15.4478 & $0.0000^{* * *}$ \\
$(-10,5)$ & 12.5984 & $0.0000^{* * *}$ & 17.5134 & $0.0000^{* * *}$ & 13.1941 & $0.0000^{* * *}$ \\
\hline \hline
\end{tabular}

Notes: $* * *, * *$ and $*$ respectively Indicate statistical significance at the $1 \%, 5 \%$ and $10 \%$ level.

\section{Empirical Analysis on the Influencing Factors of the Market effects of Private Placement}

5.1 Variables selection. This section will try to study the factors that influence the announcement effect and will take the cumulative abnormal return rates (CARs) during the window period $(0,5)$ as a proxy variable to measure the level of the announcement effect. In the meanwhile, in order to further study the effects of insider trading on the announcement effect, we will take CARs during the window period $(-10,-1)$ as a proxy variable and add it as an independent variable to the multiple regression model. According to related literature and hypothesis, following factors are selected (Tab.2): 
Tab.2 Selected Variables

\begin{tabular}{|c|c|c|}
\hline $\begin{array}{l}\text { Types } \\
\text { Dependent } \\
\text { Variable } \\
\end{array}$ & $\begin{array}{l}\text { Names and Symbols } \\
\text { The Cumulative Abnormal } \\
\text { Return Rate (CAR) }\end{array}$ & $\begin{array}{l}\text { Explanation } \\
\text { The cumulative abnormal return rate after the announcement of the } \\
\text { private placement, during the window period }(0,5)\end{array}$ \\
\hline \multirow{9}{*}{$\begin{array}{l}\text { Independent } \\
\text { Variables }\end{array}$} & Discount Rate（Discount） & $\begin{array}{l}\text { (The closing price on the day before the pricing benchmark - the } \\
\text { planned new share price for private placement)/ The closing price } \\
\text { on the day before the pricing benchmark }\end{array}$ \\
\hline & Participation of Major & Dummy variable \\
\hline & Shareholders`（BJ ) & ( Participant $=1$, non-participant $=0$ ) \\
\hline & Participation of Specific Investors & Dummy variable \\
\hline & (Investor) & ( Participant=1, non-participant $=0$ ) \\
\hline & Insider Trading（CAR10） & $\begin{array}{l}\text { The cumulative abnormal return rate before the announcement of } \\
\text { the private placement, during the window period }(-10,-1)\end{array}$ \\
\hline & Relative issue size（Size） & $\begin{array}{c}\text { The number of additional shares issued/The total share capital after } \\
\text { private placement }\end{array}$ \\
\hline & $\begin{array}{l}\text { Total market value of the } \\
\text { company before private } \\
\text { placement (CAP) }\end{array}$ & Share price*The number of issued-and-outstanding stocks \\
\hline & $\begin{array}{l}\text { Proportion of major shareholders } \\
\text { to subscribe }(\mathrm{SH})\end{array}$ & $\begin{array}{l}\text { The subscription amount of major shareholders in the private } \\
\text { placement }\end{array}$ \\
\hline \multirow{4}{*}{$\begin{array}{l}\text { Controlled } \\
\text { Variable }\end{array}$} & Return on Net Assets （ROE） & The average return on net assets over the previous year \\
\hline & Turnover Rate（Turnover） & $\begin{array}{c}\text { The average daily exchange rate in the month of the private } \\
\text { placement }\end{array}$ \\
\hline & Asset-liability Ratio（Debt） & The asset-liability ratio of the previous year \\
\hline & The market environment (EN) & $\begin{array}{c}\text { The CSI } 300 \text { index cumulative yield in the month of the private } \\
\text { placement }\end{array}$ \\
\hline
\end{tabular}

5.2 Model Design. Multiple regression models were used to analyze, as following:

CAR $=\beta_{0}+\beta_{1} \mathrm{BJ}+\beta_{2}$ Specialinvestor $+\beta_{3}$ Discount $+\beta_{4}$ size $+\beta_{5}$ CAP $+\beta_{6}$ turnover +

$\beta_{7} \mathrm{ROE}+\beta_{8} \mathrm{debt}+\beta_{9} \mathrm{EN}+\beta_{10} \mathrm{CAR} 10+\varepsilon_{\mathrm{i}}$

$\beta_{0}$ represents the intercept; $\beta_{1}, \beta_{2}, \beta_{3}, \ldots$ and $\beta_{10}$ represent the regression coefficients; $\varepsilon_{i}$ presents random interference.

\subsection{Descriptive Statistics}

Tab.3 represents descriptive statistics of all the selected variables:

Tab.3 Descriptive Statistics of All the Selected Variables

\begin{tabular}{ccccccc}
\hline \hline & Mean & Median & Maximum & Minimum & Std. Dev. & Observations \\
\hline CAR05 & 0.131 & 0.062 & 0.612 & -0.396 & 0.212 & 867 \\
CAR10 & 0.039 & 0.041 & 0.574 & -0.363 & 0.092 & 867 \\
DEBT & 47.995 & 47.678 & 142.395 & 2.439 & 21.772 & 867 \\
DISCOUNT & 31.067 & 29.040 & 88.950 & -102.850 & 25.671 & 867 \\
EN & 0.032 & 0.019 & 0.258 & -0.156 & 0.079 & 867 \\
ROE & 6.222 & 5.745 & 73.783 & -142.225 & 13.146 & 867 \\
SH & 16.330 & 0.000 & 100.000 & 0.000 & 30.242 & 867 \\
SIZE & 0.179 & 0.144 & 0.927 & 0.002 & 0.152 & 867 \\
INVESTOR & 0.362 & 0.000 & 1.000 & 0.000 & 0.481 & 867 \\
TURNOVER & 3.343 & 2.406 & 28.264 & 0.009 & 3.218 & 867 \\
CAP & 83.503 & 45.304 & 1801.361 & 7.395 & 141.023 & 867 \\
\hline \hline
\end{tabular}

\subsection{Regression results}

The regression test results of Model $\mathrm{I}$ is shown in Tab.4: 
Tab.4 The Regression Test Results of Model

\begin{tabular}{cccc}
\hline \hline Variable & Coefficient & t-Statistic & Prob. \\
\hline CAP & 0.0000 & 0.4301 & 0.6672 \\
DEBT & -0.0009 & -3.1117 & $0.0019^{* * *}$ \\
DISCOUNT & 0.0035 & 12.8483 & $0.0000^{* * *}$ \\
EN & 0.1355 & 1.7214 & $0.0855^{*}$ \\
ROE & -0.0001 & -0.2696 & 0.7876 \\
SIZE & 0.1183 & 2.7700 & $0.0057^{* * *}$ \\
INVESTOR & 0.0278 & 2.0183 & $0.0439^{* *}$ \\
TURNOVER & 0.0073 & 3.7451 & $0.0002^{* * *}$ \\
BJ & -0.0495 & -3.7746 & $0.0002^{* * *}$ \\
CAR10 & -0.3108 & -4.6965 & $0.0000^{* * *}$ \\
R-squared & 0.3109 & & \\
Adjusted R-squared & 0.3029 & & \\
F-statistic & 38.6250 & & \\
Prob(F-statistic) & $0.0000^{* * *}$ & & \\
\hline \hline
\end{tabular}

Notes: $* * *, * *$ and $*$ respectively Indicate statistical significance at the $1 \%, 5 \% a n d 10 \%$ level.

As for the overall regression result, although the general adjustment $R^{2}$ of the model is in a moderate degree, it is still acceptable. Considering the stock market affected by the policy, macro economy and industry prospects and other factors, it is difficult to fully explain the results. so the result is acceptable.

As for the variables, the coefficient of relative issue size is positive and significant at the confidence level of $1 \%$, suggesting that larger the relative size of the private placement is, greater effects will the private placement have on the listed companies. So will the market's attention. In practice, private placement in the asset reorganization mode comes first in the relative issue size, thus it will bring positive announcement effect more strongly; The discount rate is positive and significant at the confidence level of $1 \%$. Higher the discount rate is, stronger the announcement effects in the market will be, vice versa; The coefficient of the predetermined investors participation is positive and significant at the confidence level of $5 \%$. When the predetermined investors are involved, the announcement effect is stronger compared with that without predetermined investors. Because their participation stimulates imagination of the reasons for the private placement. In this way, the market tends to believe that the predetermined investors and the listed companies have more interests in common, and the latter has the motivation of managing the market value, often leading to expectation of rise in the stock price.it will have a positive effect on the announcement effect.

The coefficient of Participation of Major Shareholders is negative and significant at the confidence level of $1 \%$, indicating that large shareholders' participation will reduce the strength of the announcement effect. At present, the consideration of the private placement is usually paid by major shareholders in the form of assets. As a result, the assets are inclined to be overvalued. It is not uncommon to inject some bad assets, which will depress the share price and therefore weaken the announcement effect; The coefficient of the proxy variable of insider trading effect is negative and significant at the confidence level of $1 \%$, indicating that the insider trading effect is negatively correlated to the announcement effect, which means that insider trading behaviors will damage the announcement effect, drain the benefits of private placements of listed companies and may infringe on the rights and interests of other investors.

In terms of control variables, the coefficient of the asset-liability ratio and significant at the confidence level of $1 \%$. The lower the asset liability ratio of the listed company is, the stronger the market announcement effect will be, the higher risk will the financial leverage face, the more conservative the market will be. In other words, the asset-liability ratio is negatively correlated to 
the announcement effect.

The turnover rate measures the sentiment of investors and the stock liquidity. Its coefficient is positive and significant at the confidence level of $1 \%$. The higher the turnover rate is, the more active are the investors, and the better the stock liquidity and the market announcement effect will be; The coefficient of the market environment is positive and significant at the confidence level of $10 \%$, suggesting that the announcement effect of private placement is influenced by the market environment, the better the external environment is, the stronger the effect will be.

Return on net assets and the company's market value have insignificant impacts on the market announcement effect, as both variables do not pass the test.

5 .5 The Multi-Collinearity Test. To ensure the model's accuracy, the variance inflation factor (VIF) method is introduced. Using EViews software to carry out the test of multi-collinearity, If the Centered VIF values are greater than 5, the model has a multiple mutual linear problem. But the test values of all the variables in the model are less than 5 , so the model is free from problem of multi-collinearity.

\section{Summary}

\subsection{Private Placement Produces Positive Announcement Effect as Well as Behaviors of Insider} Trading. The empirical analysis shows that the private placement incidents of Chinese A-share listed companies lead to significant positive market effects. Different types of private placement shall have different levels of market effects and different abnormal return distributions. The accumulated average abnormal return of the private placement in the asset injection mode ranks the second, while those of the project financing private placement is the worst among the market effects. We also find that before the announcement day, obvious positive abnormal return appeared. The abnormal return has disappeared soon after the announcement day. It shows that the private placement bull has been digested by the market in advance and there are the behaviors

6.2 Many Factors Affect the Private Placement Announcement Effect. For the features of the private placement, the scale of the private placement shall have a obviously positive influence on the announcement effect. When the predetermined investors participate in, the market announcement effect shall be stronger, There is a negative correlation between the large shareholders' participation and the announcement effect. There is a positive correlation between the rate of discount and the private placement announcement effect and significant negative correlation between the behaviors of insider trading and the announcement effect. The behaviors of insider trading shall damage the market announcement effect of the private placement to some degree. The greater the insider trading effect is, the weaker the announcement effect will be. The company size has failed to pass the test.

For the company financial indexes, the asset-liability ratio shall have a negative influence on the announcement effect. The companies with the higher financial leverage shall face greater financial risk. The influence of net assets income rate on the announcement effect fails to pass the examination either. The company's profitability has no significant influence on the short-term announcement effect.

For the market environment, the announcement effect is greatly influenced by the market environment. In the bull market, the announcement effect shall be stronger, the listed companies shall have the higher turnover rate, the stock liquidity is better and its announcement effect shall be stronger.

6.3 Suggestions for the Small and Middle-Sized Investors' Decision-Making. The private placement has been recognized and accepted by the Chinese A-share market. However, it is worth studying how the small and middle-sized investors can better participate in the private placement given their disadvantage of information and capital. The paper concludes that the small and middle-sized investors can only conduct a transaction after the private placement announcement; they should read the plans of the private placement at first to know the private placement type of the company; for the asset reorganization private placement, they can look for the opportunity to enter and try to sell the stocks to obtain the excess earnings within five trading days after the 
announcement day; for the asset injection private placement, they should try to conduct the operation within the three trading days after announcement day; for the project financing private placement, they are not expected to invest. If the share price has been the peak value of the accumulated excess earnings caused by the announcement effect, it is not the right time for them to invest any more.

\section{Reference}

[1] Alexander Kurov, Investor Sentiment and the Stock Market's Reaction to Monetary Policy, Journal of Banking and Finance (2009)

[2] Asquith, Mullins, Equity Issue and Offering Dilution, Journal of Financial Economics, Vol.15,(1986)

[3] Hamish D. Anderson, Lawrence C. Rose, Steven F. Cahan, Differential Shareholder Wealth and Volume Effects Surrounding Private Equity Placements in New Zealand, Pacific-Basin Finance Journal, Vol. 14 ,(2006)

[4] Hertzel Miehael G, Richard L. Smith, Market Discounts and Shareholder Gains for Placing Equity Privately, Journal of Finance, Vol.48,(1993)

[5] Hertzel, M., \& Rees, L. Earnings and risk changes around private placements of equity. Journal of Accounting, Auditing and Finance, Vol. 13, (1998). pp .21-35 